\title{
Aluminium and base cation chemistry in dynamic acidification models - need for a reappraisal?
}

\author{
Jon Petter Gustafsson ${ }^{1,2}$, Salim Belyazid ${ }^{3}$, Eric McGivney ${ }^{1}$, and Stefan Löfgren ${ }^{4}$ \\ ${ }^{1}$ Department of Sustainable Development, Environmental Science and Engineering, KTH Royal Institute \\ of Technology, Teknikringen 10B, 100 44, Stockholm, Sweden \\ ${ }^{2}$ Department of Soil and Environment, Swedish University of Agricultural Sciences, \\ P.O. Box 7014, 75007 Uppsala, Sweden \\ ${ }^{3}$ Department of Physical Geography, Stockholm University, 10691 Stockholm, Sweden \\ ${ }^{4}$ Department of Aquatic Sciences and Assessment, Swedish University of Agricultural Sciences, \\ P.O. Box 7050, 75007 Uppsala, Sweden
}

Correspondence: Jon Petter Gustafsson (gustafjp@kth.se)

\author{
Received: 19 June 2018 - Discussion started: 29 June 2018 \\ Revised: 8 October 2018 - Accepted: 18 October 2018 - Published: 26 October 2018
}

\begin{abstract}
Long-term simulations of the water composition in acid forest soils require that accurate descriptions of aluminium and base cation chemistry are used. Both weathering rates and soil nutrient availability depend on the concentrations of $\mathrm{Al}^{3+}$, of $\mathrm{H}^{+}$, and of base cations $\left(\mathrm{Ca}^{2+}, \mathrm{Mg}^{2+}, \mathrm{Na}^{+}\right.$, and $\left.\mathrm{K}^{+}\right)$. Assessments of the acidification status and base cation availability will depend on the model being used. Here we review in what ways different dynamic soil chemistry models describe the processes governing aluminium and base cation concentrations in the soil water. Furthermore, scenario simulations with the HD-MINTEQ model are used to illustrate the difference between model approaches. The results show that all investigated models provide the same type of response to changes in input water chemistry. Still, for base cations we show that the differences in the magnitude of the response may be considerable depending on whether a cation-exchange equation (Gaines-Thomas, Gapon) or an organic complexation model is used. The former approach, which is used in many currently used models (e.g. MAGIC, ForSAFE), causes stronger $\mathrm{pH}$ buffering over a relatively narrow $\mathrm{pH}$ range, as compared to state-of-the-art models relying on more advanced descriptions in which organic complexation is important (CHUM, HD-MINTEQ). As for aluminium, a "fixed" gibbsite constant, as used in MAGIC, SMART/VSD, and ForSAFE, leads to slightly more pH buffering than in the more advanced models that consider both organic complexation and $\mathrm{Al}(\mathrm{OH})_{3}(\mathrm{~s})$ precipitation, but in this case the effect is small. We conclude that the descriptions of acid-base chemistry and base cation binding in models such as MAGIC, SMART/VSD, and ForSAFE are only likely to work satisfactorily in a narrow $\mathrm{pH}$ range. If the $\mathrm{pH}$ varies greatly over time, the use of modern organic complexation models is preferred over cation-exchange equations.
\end{abstract}

\section{Introduction}

Acid rain has been an environmental issue of concern ever since Svante Odén presented his famous newspaper article in 1967, in which the acidification of water systems in the Northern Hemisphere was first described (Odén, 1967). Most of the atmospheric acid deposition was caused by sulfur emissions from fossil fuel combustion. In Europe and North America successful efforts were finally made to re- duce the emissions, and in 2014 the atmospheric sulfur emissions in western Europe were less than $20 \%$ of what they were around 1970, when the emissions peaked (Engardt et al., 2017). Despite the drastic cuts of emissions, there are still acidified soils and waters for which the critical loads are exceeded at the current atmospheric $S$ deposition level. In 1980, the critical loads were exceeded for $58 \%$ of all Swedish lakes. In 2030, exceedances are expected for be- 
tween $3 \%$ and $22 \%$ of the lakes (Moldan et al., 2017). The exact figure depends mostly on the intensity of forest harvesting (Akselsson et al., 2007; Iwald et al., 2013). The latter leads to net removal of base cations, and is therefore also an acidifying process that affect the critical loads (Nilsson et al., 1982). Hence, problems with soil and water acidification could persist even though the atmospheric deposition is cut to very low levels.

For a long time dynamic acidification models have been valuable tools to understand the underlying mechanisms and to produce scenarios for long-term acidification effects. Most of the dynamic acidification models in use today have their roots in ideas and concepts developed in the 1970s and 1980s. For example, cation sorption was viewed as an exchange process in which $\mathrm{Ca}^{2+}, \mathrm{Mg}^{2+}, \mathrm{Na}^{+}, \mathrm{K}^{+}, \mathrm{H}^{+}$, and $\mathrm{Al}^{3+}$ competed for a limited number of exchange sites. This view persisted despite the fact that many of acidified sites had soils rich in organic matter but with a low clay percentage. In addition, the mechanisms responsible for $\mathrm{Al}$ dissolution were still poorly understood at the time.

It was not until the late 1980s that it was suggested that the Al solubility in many surface horizons was controlled by organic matter complexation (Mulder et al., 1989), and a few years later it was shown that the $\mathrm{pH}$-dependent dissolution of Al deviated significantly from the cubic relationship expected from equilibrium with an $\mathrm{Al}(\mathrm{OH})_{3}$-type phase (Mulder and Stein, 1994; Berggren and Mulder, 1995; Wesselink and Mulder, 1995). Moreover, with the development of organic complexation models such as WHAM, it was shown that the solubility of base cations was better described when the variable-charge nature of organic matter was taken into account (Tipping and Hurley, 1992; Tipping et al., 1995). Since then, modern organic complexation models such as WHAM, NICA-Donnan (Kinniburgh et al., 1999), and the Stockholm Humic Model (SHM; Gustafsson, 2001) have been applied to numerous soil systems, and the results showed the correctness of the above conclusions (e.g. Lofts et al., 2001; Weng et al., 2002; Gustafsson and Kleja, 2005).

Despite these findings, many of the most used dynamic acidification models such as ForSAFE (Warfvinge et al., 1993; Wallman et al., 2005), MAGIC (Cosby et al., 1985, 2001), and SMART/VSD (de Vries et al., 1989; Posch and Reinds, 2009) are not updated with these more modern process descriptions. In the following, we refer to these models as "ion-exchange" models, as the solid-solution interactions are based primarily on ion-exchange equations. However, some dynamic models have been developed that contain updated descriptions. These are CHUM-AM (Tipping, 1996; Tipping et al., 2006), which uses WHAM, and SMARTml (Bonten et al., 2011), which includes the NICA-Donnan model. Recently, the HD-MINTEQ model was added to this list (Löfgren et al., 2017). HD-MINTEQ uses the SHM as a basis. However, the latter models have (at least so far) been less used in acidification research.
The purpose of this paper is to review the process descriptions of currently used models as regards to base cations and aluminium, and then to investigate the difference in model performance between the two types of model mentioned above, i.e. between ion-exchange models and organic complexation models. Based on parameter values from the Gårdsjön integrated monitoring site in southwest Sweden, this is done through hypothetical scenario simulations in which the atmospheric deposition of $S$ and sea salt is varied in steps. Compared with using complex "real-world" data, this approach makes it possible to isolate the effect of the different model descriptions from other processes that affect soil chemistry (see Methods). Thus, the nature of the modelled response is compared and no attempt is made to "validate" a certain model description. The results suggest that the difference in model performance is rather small as long as the $\mathrm{pH}$ remains within a confined $\mathrm{pH}$ range; the most significant differences are seen for proton buffering and for base cation dynamics.

\section{Aluminium and base cations in dynamic acidification models - review}

\subsection{Aluminium and base cations in ion-exchange models}

In MAGIC and SAFE/ForSAFE, as well as in the SMART/VSD models, a "gibbsite equilibrium", i.e. a cubic relationship between the $\mathrm{Al}^{3+}$ and $\mathrm{H}^{+}$activities, $\left\{\mathrm{Al}^{3+}\right\}$ and $\left\{\mathrm{H}^{+}\right\}$, is used to calculate $\left\{\mathrm{Al}^{3+}\right\}$ from $\mathrm{pH}$, according to

$K_{G}=\frac{\left\{\mathrm{Al}^{3+}\right\}}{\left\{\mathrm{H}^{+}\right\}^{3}}$.

In the models, the $K_{G}$ value is treated as a fitting parameter that is optimized from measurements/estimates of $\mathrm{pH}$ and $\left\{\mathrm{Al}^{3+}\right\}$ in a given soil horizon. In other words, there is not necessarily any a priori assumption involved that states than an $\mathrm{Al}(\mathrm{OH})_{3}$ (s) phase governs $\left\{\mathrm{Al}^{3+}\right\}$. Rather, Eq. (1) should be seen as a practical way of accounting for Al solubility, which may hold if $\mathrm{pH}$ and $\left\{\mathrm{Al}^{3+}\right\}$ do not vary much over time (i.e. so that the ion activity product of $\mathrm{Al}(\mathrm{OH})_{3}(\mathrm{~s})$ remains constant).

Sorption (and desorption) of base cations is treated as an exchange process in the traditional models, where cations compete for a constant number of exchange sites. In MAGIC (Cosby et al., 1985, 2001), the Gaines-Thomas cationexchange formalism is used. Four equations are used for describing the exchange of $\mathrm{Al}^{3+}$ with $\mathrm{Ca}^{2+}, \mathrm{Mg}^{2+}, \mathrm{Na}^{+}$, and $\mathrm{K}^{+}$. In the case of Al-Ca exchange, the equation reads

$K_{\mathrm{GT}, \mathrm{Al}-\mathrm{Ca}}=\frac{E_{\mathrm{Ca}}^{3}\left\{\mathrm{Al}^{3+}\right\}^{2}}{E_{\mathrm{Al}}^{2}\left\{\mathrm{Ca}^{2+}\right\}^{3}}$,

where $K_{\mathrm{GT}, \mathrm{Al}-\mathrm{Ca}}$ is the selectivity coefficient for $\mathrm{Al}-\mathrm{Ca}$ exchange, and $E_{\mathrm{Al}}$ and $E_{\mathrm{Ca}}$ are the equivalent fractions of exchangeable $\mathrm{Al}^{3+}$ and $\mathrm{Ca}^{2+}$, respectively. The $\mathrm{Al}(\mathrm{OH})_{3}(\mathrm{~s})$ 
equilibrium (cf. above) is used to fix $\left\{\mathrm{Al}^{3+}\right\}$. Further, in MAGIC the activities of exchangeable $\mathrm{H}^{+}$and of other exchangeable ions (e.g. $\mathrm{Fe}^{3+}, \mathrm{Mn}^{2+}$ ) are not considered. According to Cosby et al. (2001) this is because these are assumed to be insignificant. Hence the cation-exchange capacity (CEC), i.e. the total number of exchange sites, is considered to be the sum of exchangeable base cations and exchangeable $\mathrm{Al}^{3+}$. The sum of exchangeable fractions is 1 ;

$E_{\mathrm{Al}}+E_{\mathrm{Ca}}+E_{\mathrm{Mg}}+E_{\mathrm{Na}}+E_{\mathrm{K}}=1$.

During calibration of the MAGIC model, it is usually assumed that the CEC can be estimated using a conventional extraction of exchangeable acidity (e.g. $1 \mathrm{M} \mathrm{KCl}$ ). By using data for exchangeable base cations (e.g. by $1 \mathrm{MNH}_{4} \mathrm{Cl}$ ) the equivalent fractions of all cations can be estimated. If solution data are available or can be estimated, Eq. (2) can then be used to calculate selectivity coefficients. The optimized coefficients should be regarded as site-specific; i.e. they cannot be generalized to other soils or even to other soil layers. This has been identified as a weak point of the ion-exchange models when comparing them to more process-oriented models such as CHUM-AM and SMARTml, for which site-specific optimization of any constants or selectivity coefficients should not be necessary (Bonten et al., 2011).

In the SAFE/ForSAFE suite of models (Warfvinge et al., 1993; Wallman et al., 2005) the Gapon ion-exchange equation is used instead of the Gaines-Thomas equation, and in the SMART and VSD models (de Vries et al., 1989; Posch and Reinds, 2009) the user can choose between these two equations. In the standard versions of these models the base cations $\mathrm{Ca}^{2+}, \mathrm{Mg}^{2+}$ and $\mathrm{K}^{+}$are bulked into a single entity, $\mathrm{BC}^{2+}$, where $\mathrm{K}^{+}$is treated as a divalent ion, whereas $\mathrm{Na}^{+}$ is usually not considered at all. As a consequence, no more than three exchange equations need to be considered, which describe $\mathrm{Al}-\mathrm{BC}, \mathrm{H}-\mathrm{BC}$, and $\mathrm{H}-\mathrm{Al}$ exchange. For example, in the case of $\mathrm{Al}-\mathrm{BC}$ exchange, the Gapon equation reads

$K_{\mathrm{G}, \mathrm{AlBC}}=\frac{E_{\mathrm{BC}}\left\{\mathrm{Al}^{3+}\right\}^{1 / 3}}{E_{\mathrm{Al}}\left\{\mathrm{BC}^{2+}\right\}^{1 / 2}}$.

The number of equations required can be further reduced to two through the gibbsite equilibrium, which fixes $\left\{\mathrm{Al}^{3+}\right\}$ as a function of $\left\{\mathrm{H}^{+}\right\}$(Warfvinge et al., 1993; Posch and Reinds, 2009). The calibration procedure of the SMART/VSD and the SAFE/ForSAFE models is similar to the one for MAGIC; i.e. measured exchangeable fractions (after assuming that the total number of sites is obtained from exchangeable acidity) are used to calculate values for the selectivity coefficients.

In all models, the $\mathrm{pH}$ of the soil solution is calculated from charge balance, which makes it important to correctly estimate the charge contributions from organic acids and Al-organic complexes. This is done in slightly different ways in the ion-exchange models. The SAFE/ForSAFE and SMART/VSD models use the Oliver equation (Oliver et al., 1983) to estimate the organic anion charge. Although the
Oliver equation incorporates the effect of Al-organic complexes on the calculated organic anion charge, Al-organic complexes are not considered in the mass balance of the organic anion component. To consider the effect on the mass balance of Al, the ForSAFE/SAFE models use the following empirical equation, originally suggested by Tipping et al. (1988):

$\left[\mathrm{Al}_{\mathrm{org}}\right]=\alpha[\mathrm{DOC}]\left[\mathrm{Al}^{3+}\right]^{\beta}\left[\mathrm{H}^{+}\right]^{\gamma}$,

where $\left[\mathrm{Al}_{\mathrm{org}}\right]$ is organically bound $\mathrm{Al},[\mathrm{DOC}]$ is dissolved organic carbon $\left(\mathrm{mg} \mathrm{L}^{-1}\right), \alpha=2.09 \times 10^{-7}, \beta=0.718$, and $\gamma=-1.054$. The concentration unit for $\left[\mathrm{Al}_{\text {org }}\right],\left[\mathrm{Al}^{3+}\right]$, and $\left[\mathrm{H}^{+}\right]$is $\mathrm{mol} \mathrm{L}^{-1}$.

MAGIC uses a triprotic acid model to estimate the organic anion charge (Cosby et al., 2001). This model considers the effect of Al-organic complexation by formation of two complexes between $\mathrm{Al}^{3+}$ and the organic ligand. While MAGIC is normally set up using just a single box representing a soil profile, the SAFE/ForSAFE models use three or four soil layers in sequence, which may represent different horizons of a soil profile.

\subsection{Aluminium and base cations in CHUM-AM and in HD-MINTEQ}

Tipping (1996) was the first to present a dynamic acidification model (CHUM) based on the concept of organic matter complexation as an important process for $\mathrm{Al}$ and base cation chemistry in the surface horizon of soils. In this model, WHAM (Tipping and Hurley, 1992; Tipping, 1994) was connected to submodels accounting for parameters such as water flow, micropore-macropore exchange, and reactions involving nitrogen. The model was designed to run on a daily time step, and considered temporal differences in precipitation, water contents, etc. Mineral weathering was considered with a simple power law. CHUM also included a submodel for predicting DOC in the soil solution, using the fulvic acid adsorption-desorption model of Tipping and Woof (1991). In the original version of CHUM, the sorption and desorption of base cations are assumed to only occur through electrostatic interactions and to a lesser extent (for $\mathrm{Ca}^{2+}$ and $\mathrm{Mg}^{2+}$ ) through complexation to a variably charged humic surface according to the humic ion-binding Model V in WHAM.

Later, Tipping et al. (2006) presented an updated version of CHUM called CHUM-AM, in which Model VI (Tipping, 1998) was used instead. This model has mostly been used to simulate the long-term behaviour of metals in the UK and in Switzerland (Tipping et al., 2010; Rieder et al., 2014). In one paper, the CHUM-AM model was used to simulate the changes in water chemical composition of three Cumbrian lakes over a period of 1000 years (Tipping and Chaplow, 2012). The simulated values of $\mathrm{pH}$ and dissolved major ions were in reasonable agreement with measurements made during the last $30-40$ years. 
The recently introduced HD-MINTEQ model (Löfgren et al., 2017) is intended for scenario simulations of $\mathrm{pH}$ and dissolved ions in forest soils using a weekly time step. In the study of Löfgren et al. (2017), HD-MINTEQ was used to simulate the soil chemical response to a stepwise change in $S$ deposition, with and without whole-tree harvesting. HD-MINTEQ employs the Stockholm Humic Model (SHM; Gustafsson, 2001) to estimate the binding of base cations and aluminium to the soil solid phase. $\mathrm{SO}_{4}$ adsorption is considered using the extended Freundlich equation of Gustafsson et al. (2015). Nitrogen chemistry is not explicitly simulated; instead the user supplies the concentration of dissolved $\mathrm{NO}_{3}^{-}$ and $\mathrm{NH}_{4}^{+}$in the dissolved phase as input to the model. The current version of HD-MINTEQ incorporates the PROFILE weathering model (Sverdrup and Warfvinge, 1993); for details, see McGivney et al. (2018).

CHUM-AM and HD-MINTEQ share many similarities in how they treat the reactions relevant for aluminium and base cations. In both models, the acid dissociation of humic and fulvic acid determines the amount of negative charge as well as the extent of $\mathrm{pH}$ buffering. The dissociation of a carboxylic or a phenolic acid group is defined as follows:

$$
\mathrm{ROH} \rightleftarrows \mathrm{RO}^{-}+\mathrm{H}^{+},
$$

where $\mathrm{R}$ represents the humic molecule. For this reaction there is an intrinsic dissociation constant $K_{i}$, which is defined as

$K_{i}=\frac{\left\{\mathrm{RO}^{-}\right\}\left\{\mathrm{H}^{+}\right\}}{\{\mathrm{ROH}\}} \cdot \omega$,

where $\omega$ is an electrostatic correction term, which is calculated differently in Model VI and SHM (Tipping, 1998; Gustafsson, 2001). Both models employ a discrete-site approach to describe the $\mathrm{pH}$ dependence of the dissociation of humic substances (HS). There are eight ROH sites of different acid strengths and so there are eight $K_{i}$ values. The four most strongly acid sites $(i=1-4)$ are referred to as type A sites, whereas sites 5-8 are type B sites. The most strongly acid sites probably represent mainly carboxylic acid groups, whereas the type B sites are thought to represent weaker acids such as phenolic acids. Four constants $\left(\log K_{\mathrm{A}}, \log K_{\mathrm{B}}\right.$, $\Delta p K_{\mathrm{A}}$, and $\left.\Delta p K_{\mathrm{B}}\right)$ are needed to define the eight $\log K_{i}$ values, according to

$i=1-4: \log K_{i}=\log K_{\mathrm{A}}-\Delta p K_{\mathrm{A}}$

$i=5-8: \log K_{i}=\log K_{\mathrm{B}}-\Delta p K_{\mathrm{B}}$.

The total number of proton-dissociating sites, $n\left(\mathrm{~mol} \mathrm{~g}^{-1}\right)$, is the sum of all type A and B sites. Within each site group (A or B) all sites are present in equal amounts. For fulvic acids, the total amount of type B sites is $30 \%$ (SHM) or $50 \%$ (Model VI) of the amount of type A sites, whereas for humic acids, the amount of type B sites is $50 \%$ of that of the type A sites in both models.
Cations and metals may be sorbed to the protondissociating sites through both electrostatic attraction and complexation, according to equations given elsewhere (Tipping, 1998; Gustafsson, 2001). For weakly sorbing ions such as $\mathrm{Ca}^{2+}, \mathrm{Mg}^{2+}$, and $\mathrm{K}^{+}$, electrostatic attraction will typically be the predominating mechanism in acid forest soils, whereas for $\mathrm{Al}^{3+}$ and $\mathrm{Fe}^{3+}$, complexation will be more important (Tipping, 2002). In Model VI/CHUM-AM, a mixture of mono-, bi-, and tridentate complexes is allowed to form between the metals and the organic ligands, whereas in the case of SHM, the complexation of $\mathrm{Al}^{3+}$ and $\mathrm{Fe}^{3+}$ is exclusively through the formation of bidentate complexes. In both models, the formation of $\mathrm{Al}(\mathrm{OH})_{3}(\mathrm{~s})$ and $\mathrm{Fe}(\mathrm{OH})_{3}(\mathrm{~s})$ is allowed when the solubility constants are exceeded, using the solubility data of Gustafsson et al. (2001) and Liu and Millero (1999), respectively.

\subsection{Aluminium and base cations in SMARTml}

The SMARTml model combines the SMART soil acidification model (de Vries et al., 1989) with a scaled-down version of the VSD model (Posch and Reinds, 2009), and employs Orchestra (Meeussen, 2003) for chemical equilibrium calculations. This includes cation binding to organic matter using the NICA-Donnan model (Kinniburgh et al., 1999). Similar to CHUM/AM and HD-MINTEQ, SMARTml assumes organic matter to be the predominant sorbent phase for base cations and aluminium. In addition, the use of the NICADonnan model implies that the dissociation of HS governs both proton buffering and surface charge properties. In the model, the negative charge of the humic molecules gives rise to attraction of counterions, which accumulate in the vicinity of the molecules, inside a Donnan phase, the volume of which $\left(V_{\mathrm{D}}\right)$ is given by an empirical relationship. All of the charge on the humic particle, $q\left(\mathrm{~mol}_{\mathrm{c}} \mathrm{kg}^{-1}\right)$, is assumed to be completely neutralized by counterions within the Donnan volume. This leads to the following charge balance expression:

$$
\frac{q}{V_{\mathrm{D}}}+\sum_{i} z_{i}\left(c_{\mathrm{D}, i}-c_{i}\right)=0
$$

where $c_{\mathrm{D}, i}$ is the concentration of component $i$ with charge $z_{i}$ in the Donnan volume, and $c_{i}$ is its concentration in the bulk solution (which is generally much smaller). Furthermore, the Donnan model assumes a relationship between $c_{\mathrm{D}, i}$ and $c_{i}$ :

$c_{\mathrm{D}, i}=\chi^{z_{i}} \cdot c_{i}$,

where $\chi$ is a Boltzmann term with an implicit Donnan potential; however, the latter does not need to be calculated in order to solve for $Q_{i}$ and $c_{\mathrm{D}, i}$ in Eqs. (10) and (11). The amount bound of component $i$ onto one site is given by the 
following equation:

$$
\begin{aligned}
& Q_{i}=\frac{n_{i}}{n_{\mathrm{ref}}} \\
& \cdot Q_{\max , \mathrm{ref}} \cdot \frac{\left(\widetilde{K}_{i} \cdot c_{\mathrm{D}, i}\right)^{n_{i}}}{\sum_{i}\left(\widetilde{K}_{i} \cdot c_{\mathrm{D}, i}\right)^{n_{i}}} \cdot \frac{\left\{\sum_{i}\left(\widetilde{K}_{i} \cdot c_{\mathrm{D}, i}\right)^{n_{i}}\right\}^{p}}{1+\left\{\sum_{i}\left(\widetilde{K}_{i} \cdot c_{\mathrm{D}, i}\right)^{n_{i}}\right\}^{p}},
\end{aligned}
$$

where $Q_{i}$ is the amount bound of component $i, n_{i}$ is the component-specific non-ideality parameter, $n_{\text {ref }}$ is the nonideality parameter for the reference species (usually $\mathrm{H}^{+}$), $Q_{\text {max,ref }}$ is the maximum binding capacity for the reference species, $\widetilde{K}_{i}$ is the median value of the affinity distribution for species $i$, and $p$ is the width of the distribution. To calculate the partitioning of the reacting ions, Eqs. (10-12) are solved simultaneously as described by Kinniburgh et al. (1999). The NICA-Donnan equation is applied for two sites, considering a carboxylic ("weak") and a phenolic ("strong") site, each with its own parameters, but with a common Donnan phase. Usually, the NICA-Donnan model is used for humic and fulvic acids separately.

For aluminium, SMARTml uses the same basic approach as CHUM-AM and HD-MINTEQ; i.e. it assumes Al solubility to be governed by organic complexation as long as the soil solution is undersaturated with respect to $\mathrm{Al}(\mathrm{OH})_{3}(\mathrm{~s})$. If not, equilibrium with respect to $\mathrm{Al}(\mathrm{OH})_{3}(\mathrm{~s})$ is assumed (Bonten et al., 2011). The solubility of base cations is governed mainly by electrostatic attraction to the Donnan phase of the soil humic and fulvic acid.

So far, the SMARTml model has only been applied for one site, the Solling forest, Germany, for which $\mathrm{pH}$, major ions, and trace elements of the soil solutions were simulated (Bonten et al., 2011, 2015).

\section{Methods}

\subsection{Comparison of model descriptions - general approach}

Due to the different model descriptions of base cation and aluminium chemistry, and the importance that these reactions have on the overall acid-base chemistry of forest soils, we hypothesized that modelled dissolved base cations and aluminium dynamics would be substantially different depending on the model set-ups and inputs. However, for purposeful comparisons, a number of considerations need to be made. To specifically study the differences in base cation and aluminium dynamics, other model-specific differences (e.g. how the models handle plant uptake, $\mathrm{N}$ chemistry, $\mathrm{SO}_{4}$ adsorption, etc.) need to be eliminated. For these reasons, we chose to set up the comparison as follows:

- Four models, representing different model descriptions, were defined: the "ion-exchange A", "ion-exchange B",
"SHM", and "SHM with fixed $\mathrm{Al}(\mathrm{OH})_{3}$ " models. These are described in detail below.

- To avoid software-specific differences, all models were set up in the HD-MINTEQ model framework (Löfgren et al., 2017).

- The models were set up with four sequential soil layers in which the water was infiltrated from the soil surface through the O, E, B1, and B2 horizon, with steadily reduced rates accounting for evapotranspiration. The same general soil parameters were used for all models (Table 1). The parameter values were based on observations from the Gårdsjön integrated monitoring site in southwest Sweden (cf. McGivney et al., 2018).

- Rather than using constant deposition values, the effects of sudden changes in deposition were simulated. This enabled a comparison of how quickly and in what ways the models responded to a deposition change. The deposition values for the first 20 years represent the estimated deposition in 1880 at the Gårdsjön site (Table 2), which may be seen as typical "pre-industrial" values. The deposition during the following 40 years was taken from deposition chemistry measurements in 1980 (Löfgren et al., 2011), whereas for the period between year 60 and year 120, the projected deposition for 2020 was used. We used the method of Ferm and Hultberg (1995) for estimates of dry deposition.

- To account for soil mineral weathering, the PROFILE model was used (Sverdrup and Warfvinge, 1988). The mineralogical composition shown in Table 1 was based on the mineralogy given by Sverdrup et al. (1998) for the Gårdsjön site. The mineral surface area was estimated from particle-size analysis using the relationship of Sverdrup (1996).

- $\mathrm{SO}_{4}$ adsorption was considered using the Freundlichbased model of Gustafsson et al. (2015). As no $\mathrm{SO}_{4}$ adsorption data were available for this soil, it was assumed that "some" adsorption occurred in the B horizons, using the parameter values for the Tärnsjö Bs soil studied by Gustafsson et al. (2015).

- For simplicity, the loss of base cations from the system due to plant uptake and harvest was set to zero throughout the simulation.

- In all simulations, dissolved organic $\mathrm{C}$ (DOC), $\mathrm{NH}_{4}^{+}$, and $\mathrm{NO}_{3}^{-}$were set at constant values throughout the simulation; the values given in Table 1 represent average values of these parameters for the period 19962011, based on soil lysimeter data from the Gårdsjön site (Löfgren et al., 2011). 
Table 1. Parameter values and assumptions.

\begin{tabular}{|c|c|c|c|c|}
\hline & O horizon & E horizon & B1 horizon & B2 horizon \\
\hline Soil layer thickness $(\mathrm{cm})$ & 5 & 5 & 20 & 15 \\
\hline Bulk density $\left(\mathrm{kg} \mathrm{m}^{-3}\right)$ & 156 & 773 & 749 & 836 \\
\hline Annual discharge $\left(\mathrm{m}^{3} \mathrm{~m}^{-2}\right)$ & 0.55 & 0.5 & 0.45 & 0.45 \\
\hline Soil moisture $\left(\mathrm{m}^{3} \mathrm{~m}^{-3}\right)$ & 0.3 & 0.3 & 0.3 & 0.3 \\
\hline Temperature $\left({ }^{\circ} \mathrm{C}\right)$ & 8 & 8 & 8 & 8 \\
\hline Organic C $\left(\mathrm{g} \mathrm{kg}^{-1}\right)$ & 400 & 50 & 60 & 50 \\
\hline $\mathrm{SO}_{4}$ adsorption & None & none & some $^{\mathrm{a}}$ & some $^{\mathrm{a}}$ \\
\hline $\mathrm{DOC}\left(\mathrm{mg} \mathrm{L}^{-1}\right)$ & 35 & 12.6 & 9.8 & 9.8 \\
\hline Dissolved $\mathrm{NO}_{3}^{-}(\mu \mathrm{mol} \mathrm{L}-1)$ & 0.5 & 0.4 & 0.4 & 0.4 \\
\hline Dissolved $\mathrm{NH}_{4}^{+}\left(\mu \mathrm{mol} \mathrm{L}{ }^{-1}\right)$ & 0.5 & 2.6 & 4.2 & 4.2 \\
\hline $\mathrm{CO}_{2}$ pressure (atm) & $1 \times 10^{-3}$ & $2 \times 10^{-3}$ & $7 \times 10^{-3}$ & $1 \times 10^{-2}$ \\
\hline $\log * K_{s}, \mathrm{Al}(\mathrm{OH})_{3}(\mathrm{~s})^{\mathrm{b}}$ & -4.2 & -7.7 & -9.4 & -9.4 \\
\hline \multicolumn{5}{|l|}{ PROFILE parameters } \\
\hline Mineral surface area $\left(\mathrm{m}^{2} \mathrm{~g}^{-1}\right)$ & 0 & 1.2 & 1.1 & 2.0 \\
\hline $\mathrm{K}$ feldspar $(\%)$ & 0 & 15 & 18 & 19 \\
\hline Plagioclase (\%) & 0 & 14 & 15 & 16 \\
\hline Hornblende (\%) & 0 & 0.5 & 1.5 & 1.5 \\
\hline Epidote $(\%)$ & 0 & 0.5 & 0.75 & 1.0 \\
\hline Garnet (\%) & 0 & 0.1 & 0.1 & 0.1 \\
\hline Biotite (\%) & 0 & 0.5 & 0.5 & 0.5 \\
\hline Chlorite (\%) & 0 & 0.4 & 0.4 & 0.4 \\
\hline Vermiculite (\%) & 0 & 3.0 & 15 & 5.0 \\
\hline Apatite $(\%)$ & 0 & 0.1 & 0.2 & 0.3 \\
\hline \multicolumn{5}{|c|}{ Parameters specific for ion-exchange model $^{\mathrm{c}}$} \\
\hline $\mathrm{CEC}\left(\mathrm{cmol}_{\mathrm{c}} \mathrm{kg}^{-1}\right)$ & $18.7 / 23.9$ & $3.62 / 4.85$ & $4.89 / 6.49$ & $4.73 / 5.61$ \\
\hline $\log K_{\mathrm{GT}, \mathrm{Al}-\mathrm{Ca}}$ & $-5.15 /-5.04$ & $-3.50 /-3.38$ & $-1.54 /-1.42$ & $0.13 / 0.20$ \\
\hline $\log K_{\mathrm{GT}, \mathrm{Al}-\mathrm{Mg}}$ & $-3.50 /-2.43$ & $-1.11 /-0.99$ & $0.48 / 0.60$ & $2.31 / 2.38$ \\
\hline $\log K_{\mathrm{GT}, \mathrm{Al}-\mathrm{Na}}$ & $-1.54 /-1.33$ & $-1.00 /-0.74$ & $-0.35 /-0.10$ & $0.35 / 0.50$ \\
\hline $\log K_{\mathrm{GT}, \mathrm{Al}-\mathrm{K}}$ & $-6.41 /-6.20$ & $-6.32 /-6.07$ & $-4.72 /-4.47$ & $-4.11 /-3.96$ \\
\hline $\log K_{\mathrm{GT}, \mathrm{Al}-\mathrm{H}}$ & $-/-4.80$ & $-/-6.76$ & $-/-7.73$ & $-/-7.11$ \\
\hline \multicolumn{5}{|l|}{ Parameters specific for SHM } \\
\hline Active humic acid $\left(\mathrm{g} \mathrm{kg}^{-1}\right)$ & 180 & 25 & 22.5 & 22.5 \\
\hline Active fulvic acid $\left(\mathrm{g} \mathrm{kg}^{-1}\right)$ & 60 & 25 & 22.5 & 22.5 \\
\hline Geochemically active $\mathrm{Al}\left(\mathrm{mmol} \mathrm{kg}^{-1}\right)$ & 40 & 50 & 80 & 80 \\
\hline
\end{tabular}

${ }^{\text {a }}$ Some $\mathrm{SO}_{4}$ adsorption - parameters for the Tärnsjö Bs1 soil (Gustafsson et al., 2015). ${ }^{\mathrm{b}}$ Only used in simulations in which the solubility of $\mathrm{Al}(\mathrm{OH})_{3}(\mathrm{~s})$ was set at a constant value. ${ }^{\mathrm{c}}$ The first value is for ion-exchange model A, and the second is for ion-exchange model $\mathrm{B}$.

Table 2. Total deposition values used in the scenarios $\left(\mathrm{mmol} \mathrm{m}^{-2} \mathrm{yr}^{-1}\right)$.

\begin{tabular}{lrrr|rr}
\hline \multirow{2}{*}{ Constituent } & \multicolumn{3}{c|}{ Acid scenario } & \multicolumn{2}{c}{ Salt scenario } \\
\cline { 2 - 6 } & Year 0-20 & Year 20-60 & Year 60-120 & Year 0-40 & Year 40-120 \\
\hline $\mathrm{SO}_{4}^{2-}$ & 12.1 & 89.5 & 12.4 & 12.1 & 18.0 \\
$\mathrm{Ca}^{2+}$ & 9.2 & 9.2 & 9.2 & 9.2 & 11.3 \\
$\mathrm{Mg}^{2+}$ & 17.5 & 17.5 & 17.5 & 17.5 & 28.5 \\
$\mathrm{~K}^{+}$ & 9.5 & 9.5 & 9.5 & 9.5 & 11.6 \\
$\mathrm{Na}^{+}$ & 166 & 166 & 166 & 166 & 264 \\
$\mathrm{Cl}^{-}$ & 201 & 201 & 201 & 201 & 315 \\
\hline
\end{tabular}


An alternative way to compare the model descriptions would have been to use real-world data concerning, e.g. deposition and plant uptake for a well-studied catchment such as Gårdsjön or Solling. However, such a comparison is more difficult to design purposefully as the input drivers (e.g. deposition) change continuously, so that a steady state in, e.g. base cation stores is never obtained. In addition, other factors affecting the overall chemical response, e.g. $\mathrm{N}$ transformations and long-term differences in the processes affecting the organic $\mathrm{C}$ balance (litterfall, decomposition, etc.), would obscure the comparison. Moreover, model initialization is always an issue, due to the lack of data on soil and water chemistry under pre-industrial conditions - this could affect the comparison between different model descriptions as well, since the back-calculation of the initial ecosystem state would depend on the exchange and solubility models used. Hence, to isolate the effect of the different descriptions of base cations and aluminium from other processes that affect soil chemistry and to validate a certain model description would be a very challenging task. Therefore, although not directly relevant to field conditions, the hypothetical scenarios as presented here provide some clues that would not be readily obtained under the inherently complex conditions in the field.

\subsection{The models - brief description and initialization}

Ion-exchange model. In the ion-exchange model, both acid-base and cation-binding reactions were conceptualized as ion-exchange reactions. The Gaines-Thomas equation, which is available as an option in the calculation core of HD-MINTEQ, was used for these reactions. Two model variants were used, termed models $\mathrm{A}$ and $\mathrm{B}$. In ion-exchange model A, the Gaines-Thomas equation was implemented as in MAGIC (described above and in Cosby et al., 2001), which did not specifically consider $\mathrm{H}^{+}$exchange. However, because this model had issues concerning the $\mathrm{O}$ horizon (cf. Results section), a second model (B) was introduced, which also considered $\mathrm{Al}-\mathrm{H}$ exchange. To consider the organic anion charge from dissolved organic carbon (DOC), the triprotic acid model of Hruška et al. (2003) was used. Further, Eq. (5) of Tipping et al. (1988) was employed to estimate organically bound $\mathrm{Al}$. To get the equivalent fractions of cations, we used results from $1 \mathrm{MNH}_{4} \mathrm{Cl}$ extractions of exchangeable base cations and from $1 \mathrm{M} \mathrm{KCl}$ extractions of exchangeable Al and acidity, performed during 2010 at the Gårdsjön site within the Integrated Monitoring programme (Löfgren et al., 2011). Water chemistry from soil lysimeters was also available from this site (Löfgren et al., 2011). With these data, it was possible to calculate the selectivity coefficients for each layer given in Table 1 . The $\log * K_{\mathrm{S}}$ value for $\mathrm{Al}(\mathrm{OH})_{3}(\mathrm{~s})$, needed to fix dissolved $\mathrm{Al}^{3+}$ in the model, was also constrained from the 2010 lysimeter data. To be consistent with previous applications of the ion-exchange mod- els, the $\log * K_{\mathrm{s}}$ value for $\mathrm{Al}(\mathrm{OH})_{3}(\mathrm{~s})$ was assumed not to be temperature-dependent.

SHM. For the simulations in which the organic complexation model SHM was used for metal binding (Gustafsson, 2001; Gustafsson and Kleja, 2005), we used the same assumptions as detailed by Löfgren et al. (2017). Briefly, it was assumed that $30 \%$ (O horizon) or $50 \%$ (other layers) of the soil organic matter was active with respect to proton and cation binding. Of the active organic matter in the O horizon, $75 \%$ was assumed to be humic acid, whereas $25 \%$ was attributed to fulvic acid. For the other horizons, these percentages were $50 \%$ and $50 \%$, respectively. This results in the humic and fulvic acid concentrations shown in Table 1. Further it was assumed that all dissolved organic matter (DOM) was geochemically active, and was assumed to be fulvic acid. Geochemically active $\mathrm{Al}$ is a fitting parameter in HD-MINTEQ (Table 1). It provides the total pool of Al in the model, and its value was kept constant during the simulation. The value of geochemically active $\mathrm{Al}$ was constrained initially by running the model using historic data for deposition (McGivney et al., 2018) and comparing the model result with lysimeter data. The value was chosen that provided the best description of both $\mathrm{pH}$ and $\mathrm{Al}$ combined.

$\mathrm{SHM}$ with fixed $\mathrm{Al}(\mathrm{OH})_{3}$. The purpose of this model was to investigate the effect of having the Al concentration fixed by an $\mathrm{Al}(\mathrm{OH})_{3}$ (s) equilibrium constant rather than letting the Al solubility be calculated from organic complexation equilibria in case the conditions were undersaturated with respect to $\mathrm{Al}(\mathrm{OH})_{3}(\mathrm{~s})$. In all other respects, the model was identical to the "pure" SHM. This model was used to investigate to what extent it matters whether a sophisticated organic complexation model is used to calculate Al solubility, or whether a gibbsite constant is sufficient. The $\mathrm{Al}(\mathrm{OH})_{3}(\mathrm{~s})$ equilibrium constants were calculated in the same way as in the ionexchange model.

Model initialization. A set of initial guesses was made of total suspension concentrations (adsorbed + dissolved) of base cations and $\mathrm{SO}_{4}$. The models were run for at least 1000 years with the 1880 deposition data to obtain steadystate conditions, and then applied to the scenarios defined below.

\subsection{Scenarios considered}

Two scenarios were designed in HD-MINTEQ to investigate the effect of sudden changes in the input deposition (Table 2). This should give information on how the models handle these disturbances, and what the roles of different cation-binding models are.

- Acid. Year 0-20: 1880 deposition; year 20-60: 1980 deposition; year 60-120: projected 2020 deposition.

- Salt. In this scenario there was a sudden increase in the sea salt deposition after 40 years, and this increased deposition remained until the end of the simulation. The 

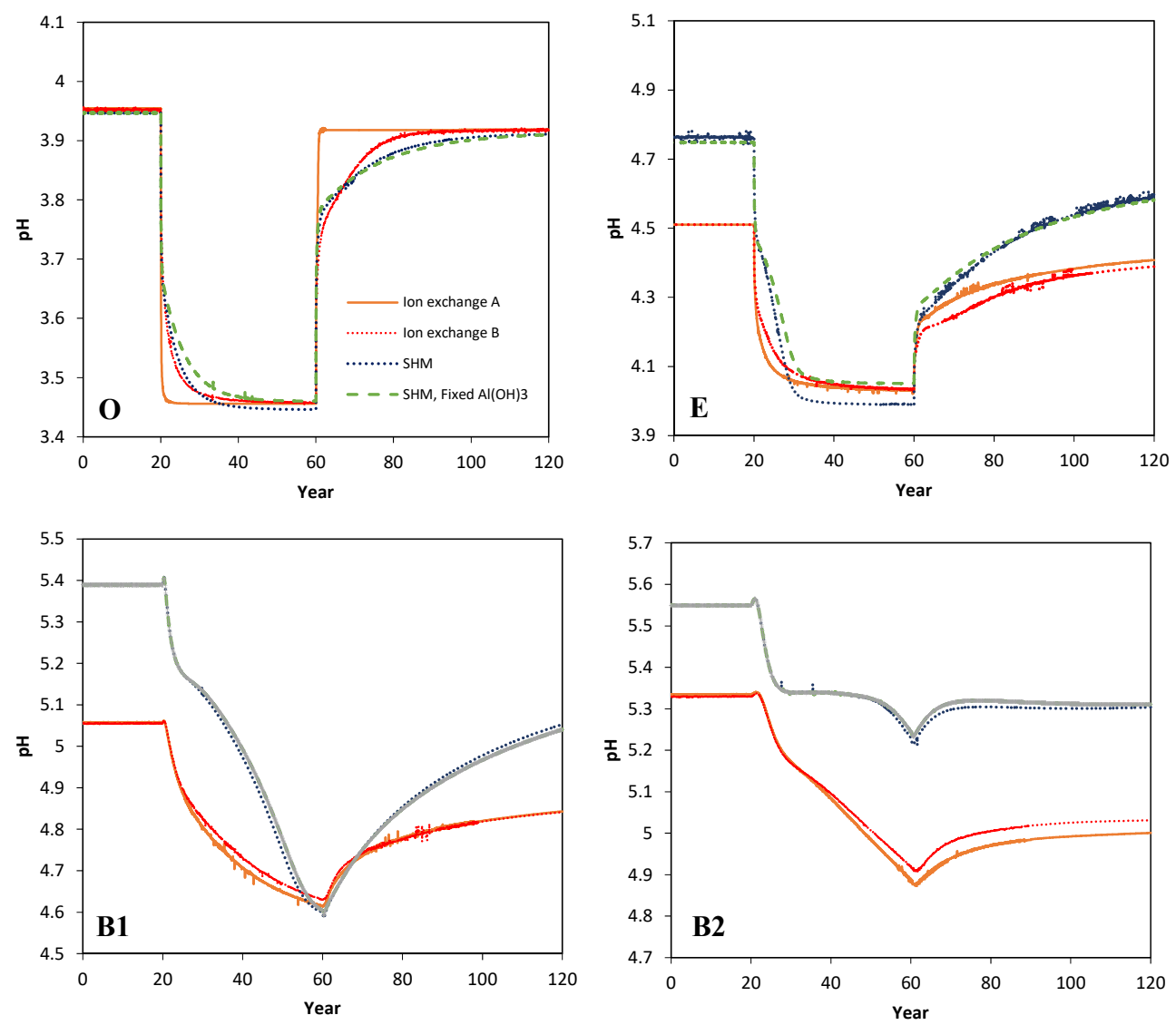

Figure 1. Simulated pH values in the four soil layers (O, E, B1, B2) as a function of time for the four models considered in the Acid scenario. For model set-up and scenario parameters, see text.

results were compared to a scenario in which the 1880 deposition remained throughout the simulation.

To further illustrate the differences between the cationbinding models used, the outcome of a titration with $\mathrm{Ca}(\mathrm{OH})_{2}$ of the $\mathrm{O}$ horizon was carried out. This was done in Visual MINTEQ 3.1 (Gustafsson, 2018) using identical parameters as in the HD-MINTEQ model simulation.

\section{Results and discussion}

\subsection{Response to changes in acid deposition}

Selected results from the Acid simulation are shown in Figs. 1, 2, and 3. All models were able to provide simulations of $\mathrm{pH}$ and dissolved $\mathrm{Ca}$ that, at first sight, may seem reasonable. However, for the $\mathrm{O}$ horizon ion-exchange model A behaved differently from the other three models in that the response of the $\mathrm{pH}$ and of dissolved $\mathrm{Ca}$ was much faster as the acid deposition changed. In addition, the concentration of exchangeable $\mathrm{Ca}$ barely changed at all, while clear responses were seen for the other models (Fig. 3). This can be attributed to the omission of exchangeable $\mathrm{H}^{+}$in ion-exchange model
A. As a result, the only constituent that could change in response to the $\mathrm{pH}$ change was $\mathrm{Al}$, which was governed by the $\mathrm{Al}(\mathrm{OH})_{3}(\mathrm{~s})$ equilibrium.

However, because the concentration of free $\mathrm{Al}^{3+}$ ions in the $\mathrm{O}$ horizon was low (in the order of $2 \times 10^{-8} \mathrm{~mol} \mathrm{~L}^{-1}$ ) the amount of $\mathrm{Al}^{3+}$ exchanged for $\mathrm{Ca}^{2+}$ during each time step was very small, causing an extremely slow response in soil water chemistry. By introducing exchangeable $\mathrm{H}^{+}$, the ionexchange model (B) behaved differently and responded to the changes in input chemistry similar to the SHM models. According to the latter three models, for the $\mathrm{O}$ horizon it would take between 10 and 20 years after a change to arrive within $0.05 \mathrm{pH}$ units from the new steady-state $\mathrm{pH}$ value, with the longer times during the recovery phase.

The above results suggest that it is necessary to include $\mathrm{H}^{+}$ exchange in dynamic ion-exchange models if organic horizons are being included as separate layers. At present this is done in ForSAFE and in SMART/VSD but not in MAGIC; however, in current practice, MAGIC is only set up for one soil layer where there is, on average, much higher dissolved $\mathrm{Al}^{3+}$. 

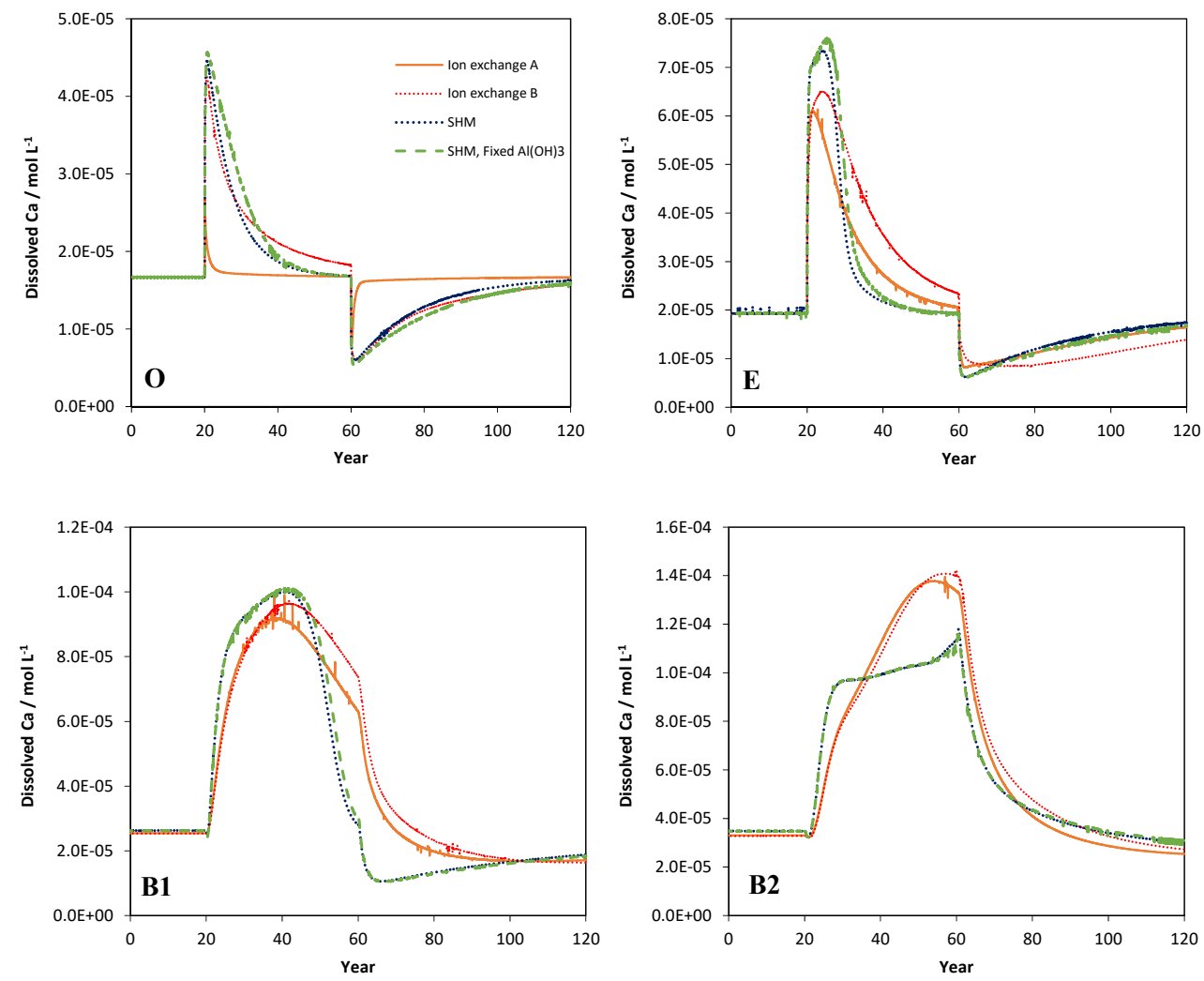

Figure 2. Simulated values of dissolved $\mathrm{Ca}$ in the four soil layers (O, E, B1, B2) as a function of time for the four models considered in the Acid scenario. For model set-up and scenario parameters, see text.

For the subsoil horizons the simulated response times were longer, in particular for the B horizons. In the latter, adsorption-desorption reactions involving both cations and $\mathrm{SO}_{4}$ were important. As $\mathrm{SO}_{4}$ adsorption was treated identically in all models, the differences observed are due to the different cation-binding models used.

The ion-exchange models and the organic complexation models predicted similar trends in $\mathrm{pH}$ and $\mathrm{Ca}$ responses to changed acid input. However, there were considerable differences in the magnitude and the exact timing of the changes. For example, the amplitude of $\mathrm{pH}$ variations in the $\mathrm{E}$ and B1 horizons was larger for the SHM models than for the organic complexation models (Fig. 1). The clearest modelspecific differences were observed for the simulated values of exchangeable $\mathrm{Ca}^{2+}$ (Fig. 3), for which the ion-exchange models predicted values between 1.5 and 4 times higher for the pre-industrial amount of exchangeable $\mathrm{Ca}^{2+}$ for the $\mathrm{O}, \mathrm{E}$, and $\mathrm{B} 1$ horizons. As a consequence, according to the SHM the stores of exchangeable $\mathrm{Ca}^{2+}$ were nearly emptied in the upper soil horizons due to the acid input, while higher values were maintained in the ion-exchange models.

\subsection{Response to changes in sea salt input}

The SHM and ion-exchange model B models, being the most sophisticated variants of the two types of model, were compared in terms of their behaviour in the Salt scenario. In qualitative terms, both models showed similar responses to a sudden increase of the sea salt input (Fig. 4). An initial dip in $\mathrm{pH}$ was followed by a slow rebound, with the fastest response times observed for the $\mathrm{O}$ horizon, whereas for the B horizons the results indicate that decades or more are required to reach a new steady state. In the models, different mechanisms were responsible for this pattern. In ion-exchange model B, increased levels of $\mathrm{Na}^{+}$and $\mathrm{Mg}^{2+}$ from the sea salt caused immediate ion exchange with $\mathrm{H}^{+}$and $\mathrm{Al}^{3+}$, with a decreased solution $\mathrm{pH}$ as a consequence. With time, however, the exchange proceeded until a new steady state was established, which was close to the old steady-state $\mathrm{pH}$. By contrast, for the SHM, the increased ionic strength of the deposition input changed the dissociation properties of soil organic matter (SOM), so that a larger fraction of SOM was dissociated at a given $\mathrm{pH}$ (cf. Gustafsson and Kleja, 2005); this led to the dissolution of $\mathrm{H}^{+}$, and consequently the $\mathrm{pH}$ was decreased. In other words, in the SHM ion exchange was not the driving mechanism, although the results bore a superficial resemblance to those expected from an ion-exchange process. 

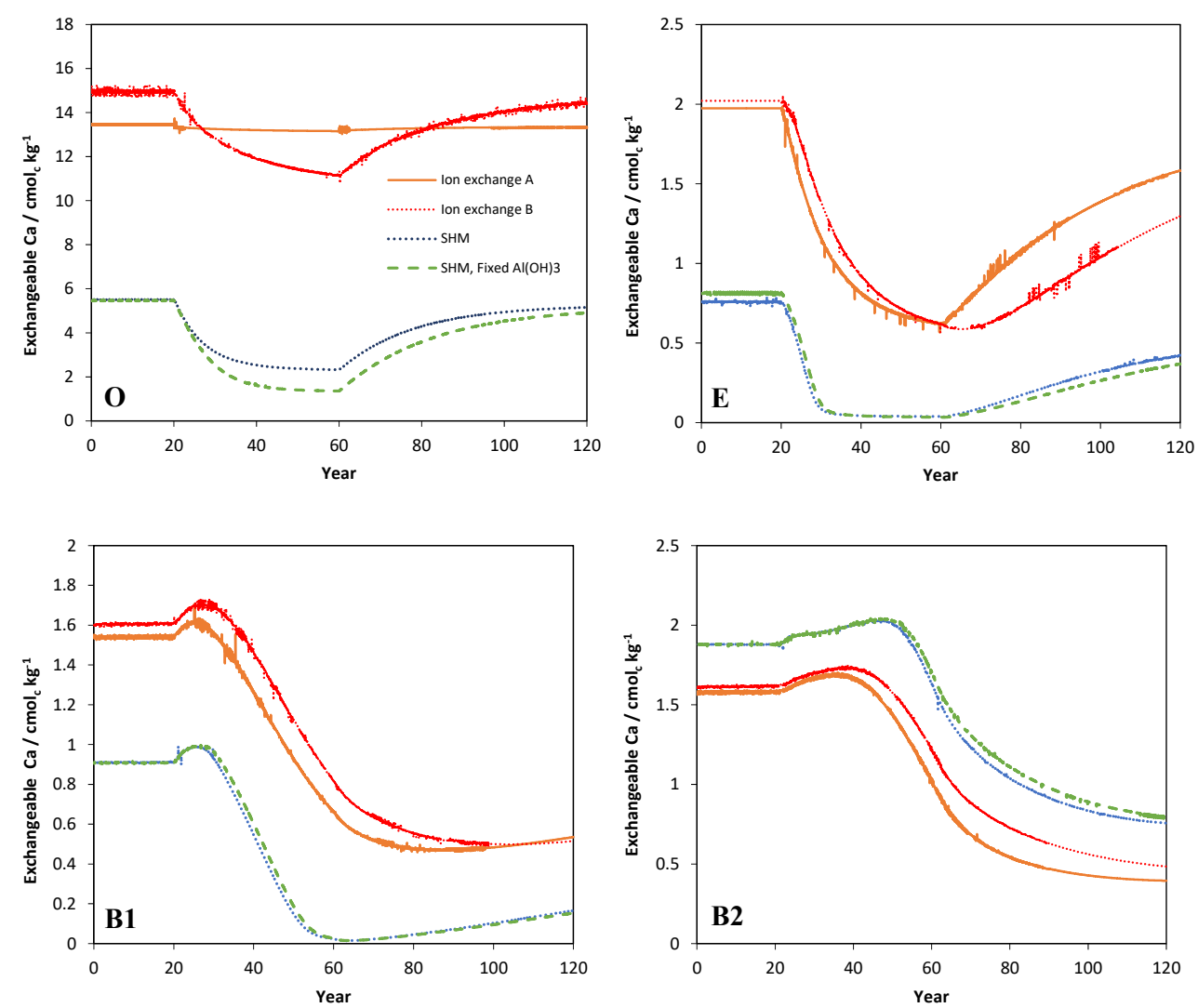

Figure 3. Simulated values of exchangeable (sorbed) $\mathrm{Ca}^{2+}$ in the four soil layers $(\mathrm{O}, \mathrm{E}, \mathrm{B} 1, \mathrm{~B} 2)$ as a function of time for the four models considered in the Acid scenario. For model set-up and scenario parameters, see text.

Again, a new steady-state $\mathrm{pH}$, being closer to the original $\mathrm{pH}$, was then slowly established with time.

As Fig. 4 shows, there were subtle but rather clear differences in how the two models simulated the temporal development of $\mathrm{pH}$. First, for SHM the new steady-state $\mathrm{pH}$ values differed more from the original ones. This can be attributed to the larger significance of ion activity coefficients in the reactions for organic complexation when compared to the Gaines-Thomas exchange equations in ion-exchange model B. Second, the rebound of $\mathrm{pH}$ towards a new steady state was slower in the case of SHM. The reason for this is not entirely clear but appears to be the result of a complex interplay of several differences between the models.

\subsection{Isolating the $\mathrm{pH}$ effect - how well do the models describe a base titration?}

To illustrate the differences in how the models handle a $\mathrm{pH}$ change, we used Visual MINTEQ 3.1 (Gustafsson, 2018) to simulate a titration in which $\mathrm{Ca}(\mathrm{OH})_{2}(\mathrm{~s})$ (which was assumed to dissolve completely) was added in steps to the Gårdsjön $\mathrm{O}$ horizon. The latter was assumed to have the chemical composition from 1880 , except that all $\mathrm{Ca}^{2+}$ was removed before the first titration step. The model simulations were made using ion-exchange model B and the two SHM models.

Although the two SHM models (with and without "fixed" gibbsite constant) performed very similarly, there were considerable differences between the SHM models and ionexchange model B (Fig. 5). For the SHM, the soil buffered the input of $\mathrm{Ca}(\mathrm{OH})_{2}(\mathrm{~s})$ over a wide $\mathrm{pH}$ range, reflecting the wide distribution of $p K_{\mathrm{a}}$ values of SOM (Gustafsson, 2001), while for the ion-exchange model, the buffering occurred over a relatively narrow $\mathrm{pH}$ range, during which the buffer curve was very steep. The results also illustrate the difference in the number of cation-binding sites: for the $\mathrm{O}$ horizon, the optimized SHM models contained about 6 times as many sites. However, most of these were not accessible to $\mathrm{Ca}^{2+}$ except at very high $\mathrm{pH}$. By contrast, for ion-exchange model $\mathrm{B}, \mathrm{Ca}^{2+}$ already occupied $70 \%$ of the exchange sites at $\mathrm{pH} 4.5$ (Fig. 5b).

\subsection{Implications}

The simple exercise shown in Fig. 5 illustrates a fundamental difference in model behaviour, a difference that should be important when discussing any model-specific differences observed in the scenarios. For example, the consistently higher 

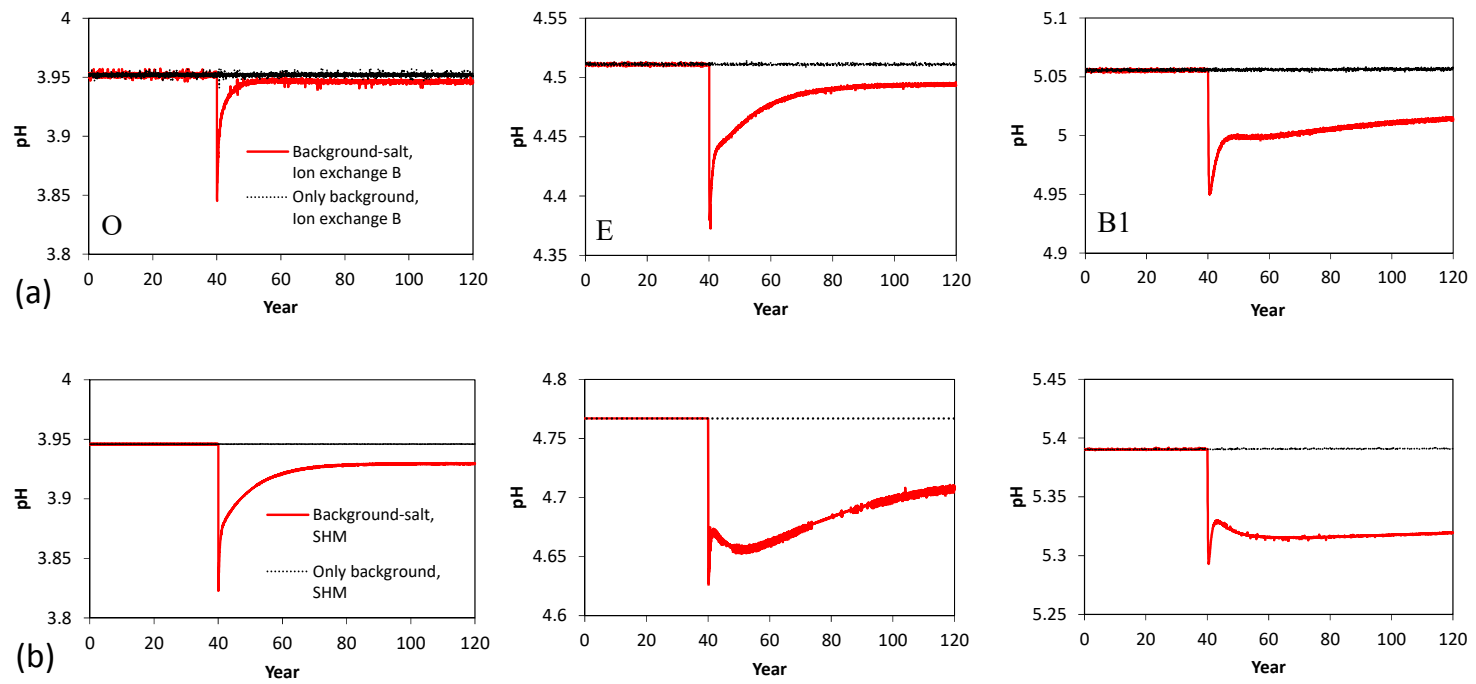

Figure 4. Simulated $\mathrm{pH}$ values following a permanent increase of the sea salt deposition after 40 years. The atmospheric deposition during years 0 to 40 (to 120 for the control simulation) was the estimated one at 1880 for the Gårdsjön site. (a) Results obtained with the ionexchange model $\mathrm{B}$, and (b) results obtained with the SHM.
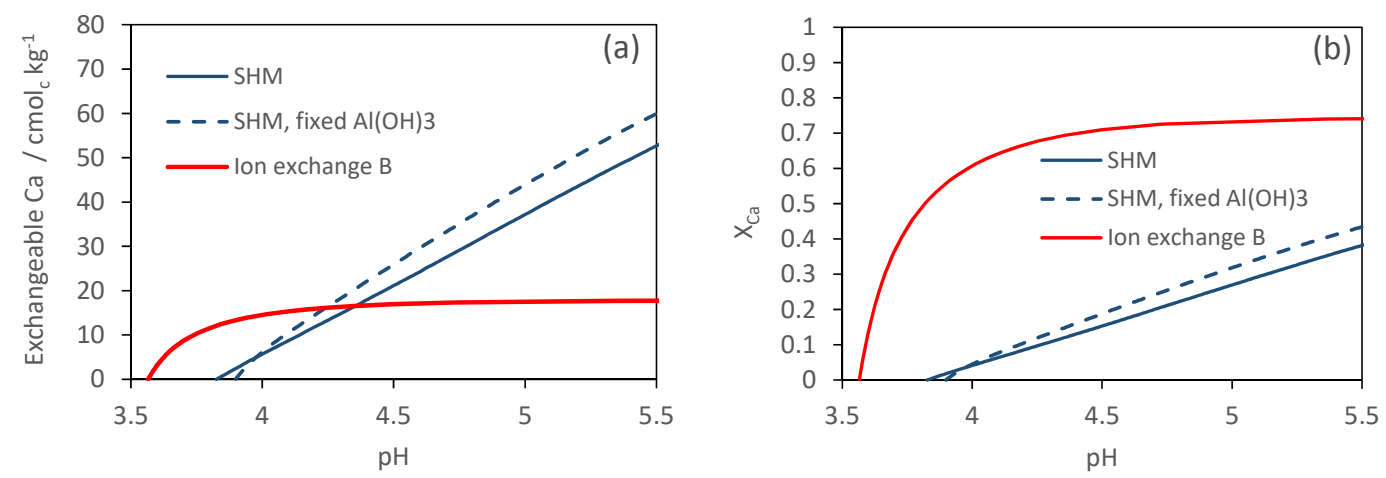

Figure 5. Model-simulated $\mathrm{Ca}(\mathrm{OH})_{2}$ titration of the Gårdsjön $\mathrm{O}$ horizon with three different models. (a) Exchangeable Ca ${ }^{2+}$ as a function of $\mathrm{pH}$, and (b) $\mathrm{X}_{\mathrm{Ca}}$ (the fraction of exchangeable $\mathrm{Ca}^{2+}$ to the total number of binding sites) as a function of $\mathrm{pH}$.

levels of pre-industrial ion-exchanged $\mathrm{Ca}^{2+}$ that the ionexchange models predict can be considered a logical consequence of the procedure to calibrate ion-exchange coefficients from present-day observations and apply the model to describe pre-industrial conditions when the $\mathrm{pH}$ was higher. This is caused by the poor ability of the ion-exchange models to describe the acid-base chemistry of the main cation sorbent in soils (i.e. organic matter) properly.

Despite this, the overall impression of the scenarios shown in Figs. 1-4 is that the differences in model performance between the two types of model were less dramatic than might have been expected, when the ion-exchange equations were integrated with other processes in a dynamic model. Overall the results do not support the view that the state-of-the-art models for organic complexation will necessarily produce much more accurate dynamic modelling results compared to the ion-exchange equations and fixed gibbsite constants currently used in the ForSAFE, SMART/VSD, and MAGIC suite of models. Other factors such as uncertainties in deposition and uptake values, and calibration procedures are likely to be of larger significance for the overall model performance.

Even so, however, there are several strong arguments for replacing the ion-exchange models with state-of-the-art organic complexation models in dynamic ecosystem models. One such argument is that the number of optimized coefficients for each simulated layer is lower for the organic complexation models (see, e.g. Table 1). Second, the empirical basis for the organic complexation models is much stronger (see, e.g. Tipping, 2002; Gustafsson and Kleja, 2005); in other words, we know from laboratory experiments that the latter are able to describe $\mathrm{pH}$ buffering and cation binding well in most acidic soils. Third, the results from the $\mathrm{Ca}(\mathrm{OH})_{2}$ (s) titration, as well as the high pre-industrial val- 
ues for exchangeable $\mathrm{Ca}^{2+}$ in the surface layers for the ionexchange models, illustrate that the ion-exchange equations currently used in ForSAFE and MAGIC are only likely to work satisfactorily within a relatively confined $\mathrm{pH}$ range. If large $\mathrm{pH}$ fluctuations occur, the inability of the ion-exchange models to consider the variable-charge properties of the sorbent can cause substantial errors in the results. As an example, this may impact the acidification classification of Swedish streams and lakes, for which MAGIC is used for estimating the $\mathrm{pH}$ difference between 1860 and the present. Moldan et al. (2013) estimated this $\mathrm{pH}$ difference to be smaller than $-0.4 \mathrm{pH}$ units in approximately 800 of 2903 lakes in 2030.

\section{Conclusions}

Ion-exchange equations, despite being relatively simplistic, predict the same type of response to changes in input chemistry as more advanced organic complexation models such as SHM, NICA-Donnan, and WHAM. This is particularly true in cases when the $\mathrm{pH}$ variations with time are relatively small. If larger $\mathrm{pH}$ variations occur, the differences in predicted $\mathrm{pH}$ and cation binding will be larger. The main reason for this is the acid-base chemistry of organic matter, for which acid dissociation occurs over a wide $\mathrm{pH}$ range. This effect is not captured correctly by the ion-exchange equations. For example, this may be an important point to consider for model initialization, as the soil water $\mathrm{pH}$ may have been much higher under pre-industrial conditions than it was later during the acid rain era. The value of exchangeable $\mathrm{Ca}^{2+}$ was found to be particularly sensitive in this regard. The method used to account for $\mathrm{Al}$ chemistry, i.e. whether or not the solubility of $\mathrm{Al}^{3+}$ is determined by a fixed gibbsite constant, was less important. Although a fixed gibbsite constant did cause stronger $\mathrm{pH}$ buffering than a more advanced model combining organic complexation and $\mathrm{Al}(\mathrm{OH})_{3}$ precipitation, the effect was rather small. In summary, state-of-the-art organic complexation models should be preferred over ion-exchange equations for predicting $\mathrm{pH}$ and cation binding in dynamic acidification models, particularly if large $\mathrm{pH}$ variations occur during the simulated time period.

Data availability. Data on soil parameters at Gårdsjön are available from the Integrated Monitoring website at http://info1. ma.slu.se/im/IMeng.html (last access: 24 October 2018). The HD-MINTEQ code can be made available upon request to gustafjp@kth.se.

Competing interests. The authors declare that they have no conflict of interest.
Special issue statement. This article is part of the special issue "Quantifying weathering rates for sustainable forestry (BG/SOIL inter-journal SI)”. It is not associated with a conference.

Acknowledgements. This study was funded by the Swedish Research Council Formas (reg. no. 2011-1691) within the strong research environment "Quantifying weathering rates for sustainable forestry (QWARTS)". Partial funding to the simulations of the effect of sea salt input was provided by the Acidification programme of SLU's Environmental Monitoring and Assessment.

Edited by: Boris Jansen

Reviewed by: two anonymous referees

\section{References}

Akselsson, C., Westling, O., Sverdrup, H., Holmqvist, J., Thelin, G., Uggla, E., and Malm, G.: Impact of harvest intensity on longterm base cation budgets in Swedish forest soils, Water Air Soil Pollut., 7, 201-210, https://doi.org/10.1007/s11267-006-9106-6, 2007.

Berggren, D. and Mulder, J.: The role of organic matter in controlling aluminum solubility in acidic mineral soil horizons, Geochim. Cosmochim. Ac., 59, 4167-4180, https://doi.org/10.1016/0016-7037(95)94443-J, 1995.

Bonten, L. T. C., Groenenberg, J. E., Meesenburg, H., and de Vries, W.: Using advanced surface complexation models for modelling soil chemistry under forests: Solling forest, Germany, Environ. Pollut., 159, 2831-2839, https://doi.org/10.1016/j.envpol.2011.05.002, 2011.

Bonten, L. T. C., Reinds, G. J., Groenenberg, J. E., de Vries, W., Posch, M., Evans, C. D., Belyazid, S., Braun, S., Moldan, F., Sverdrup, H. U., and Kurz, D.: Dynamic geochemical models to assess deposition impacts and target loads of acidity for soils and surface waters, in Critical Loads and Dynamic Risk Assessments - Nitrogen, Acidity and Metals in Terrestrial and Aquatic Ecosystems, edited by: de Vries, W., Hettelingh, J.-P., and Posch, M., Springer, 225-252, 2015.

Cosby, B. J., Wright, R. F., Hornberger, G. M., and Galloway, J. N.: Modelling the effects of acid deposition: assessment of a lumped parameter model of soil water and stream water chemistry, Water Resour. Res., 21, 51-63, https://doi.org/10.1029/WR021i001p00051, 1985.

Cosby, B. J., Ferrier, R. C., Jenkins, A., and Wright, R. F.: Modelling the effects of acid deposition: refinements, adjustments and inclusion of nitrogen dynamics in the MAGIC model, Hydrol. Earth Syst. Sci., 5, 499-518, https://doi.org/10.5194/hess-5-4992001, 2001.

de Vries, W., Posch, M., and Kämäri, J.: Simulation of the long-term soil response to acid deposition in various buffer ranges, Water Air Soil Pollut., 48, 349-390, https://doi.org/10.1007/BF00283336, 1989.

Engardt, M., Simpson, D., Schwikowski, M., and Granat, L.: Deposition of sulphur and nitrogen in Europe 1900-2050. Model calculation and comparison to historical observations, Tellus B, 69, 1328945, https://doi.org/10.1080/16000889.2017.1328945, 2017. 
Ferm, M. and Hultberg, H.: Method to estimate atmospheric deposition of base cations in coniferous throughfall, Water. Air. Soil Pollut., 85, 2229-2234, https://doi.org/10.1007/BF01186165, 1995.

Gustafsson, J. P.: Modeling the acid-base properties and metal complexation of humic substances with the Stockholm Humic Model, J. Colloid Interf. Sci., 244, 102-112, https://doi.org/10.1006/jcis.2001.7871, 2001.

Gustafsson, J. P.: Visual MINTEQ, version 3.1, available at: https: //vminteq.lwr.kth.se (last access: 24 October 2018), 2018.

Gustafsson, J. P. and Kleja, D. B.: Modeling salt-dependent proton binding with the NICA-Donnan and Stockholm Humic models, Environ. Sci. Technol., 39, 5372-5377, https://doi.org/10.1021/es0503332, 2005.

Gustafsson, J. P., Berggren, D., Simonsson, M., Zysset, M., and Mulder, J.: Aluminium solubility mechanisms in moderately acid Bs horizons of podzolised soils, Eur. J. Soil Sci., 52, 655-665, https://doi.org/10.1046/j.1365-2389.2001.00400.x, 2001.

Gustafsson, J. P., Akram, M., and Tiberg, C.: Predicting sulphate adsorption/desorption in forest soils: evaluation of an extended Freundlich equation, Chemosphere, 119, 83-89, https://doi.org/10.1016/j.chemosphere.2014.05.067, 2015.

Hruška, J., Köhler, S., Laudon, H., and Bishop, K.: Is a universal model of organic acidity possible: comparison of the acid/base properties of dissolved organic carbon in the boreal and temperate zones, Environ. Sci. Technol., 37, 1726-1730, https://doi.org/10.1021/es0201552, 2003.

Iwald, J., Löfgren, S., Stendahl, J., and Karltun, E.: Acidifying effect of removal of tree stumps and logging residues as compared to atmospheric deposition, Forest Ecol. Manag., 290, 4958, https://doi.org/10.1016/j.foreco.2012.06.022, 2013.

Kinniburgh, D. G., van Riemsdijk, W. H., Koopal, L. K., Borkovec, M., Benedetti, M. F., and Avena, M. J.: Ion binding to natural organic matter: stoichiometry and thermodynamic consistency, Coll. Surf. 151, 147-166, https://doi.org/10.1016/S09277757(98)00637-2, 1999.

Liu, X. and Millero, F. J.: The solubility of iron hydroxide in sodium chloride solutions, Geochim. Cosmochim. Ac., 63, 3487-3497, https://doi.org/10.1016/S0016-7037(99)00270-7, 1999.

Lofts, S., Woof, C., Tipping, E., Clarke, N., and Mulder, J.: Modelling $\mathrm{pH}$ buffering and aluminium solubility in European forest soils, Eur. J. Soil Sci., 52, 189-204, https://doi.org/10.1046/j.1365-2389.2001.00358.x, 2001.

Löfgren, S., Aastrup, M., Bringmark, L., Hultberg, H., LewinPihlblad, L., Lundin, L., Pihl-Karlsson, G., and Thunholm, B.: Recovery of soil water, groundwater, and streamwater from acidification at the Swedish Integrated Monitoring catchments, Ambio, 40, 836-856, https://doi.org/10.1007/s13280-011-02078, 2011.

Löfgren, S., Ågren, A., Gustafsson, J. P., Olsson, B. A., and Zetterberg, T.: Impact of whole-tree harvest on soil and stream water acidity in southern Sweden based on HD-MINTEQ simulations and pH-sensitivity, Forest Ecol. Manag., 383, 49-60, https://doi.org/10.1016/j.foreco.2016.07.018, 2017.

McGivney, E., Belyazid, S., Zetterberg, T., Löfgren, S., and Gustafsson, J. P.: Assessing the impact of acid rain and forest harvest intensity with the HD-MINTEQ model - Soil chemistry of three Swedish conifer sites from 1880 to 2080, SOIL Discuss., https://doi.org/10.5194/soil-2018-17, in review, 2018.
Meeussen, J. C. L.: ORCHESTRA: an object-oriented framework for implementing chemical equilibrium models, Environ. Sci. Technol., 37, 1175-1182, https://doi.org/10.1021/es025597s, 2003.

Moldan, F., Cosby, B. J., and Wright, R. F.: Modeling past and future acidification of Swedish lakes, Ambio, 42, 577-586, https://doi.org/10.1007/s13280-012-0360-8, 2013.

Moldan, F., Stadmark, J., Fölster, J., Jutterström, S., Futter, M. N., Cosby, B. J., and Wright, R. F.: Consequences of intensive forest harvesting on the recovery of Swedish lakes from acidification and on critical load exceedances, Sci. Total Environ., 603-604, 562-569, https://doi.org/10.1016/j.scitotenv.2017.06.013, 2017.

Mulder, J. and Stein, A.: The solubility of aluminium in acidic forest soils: long-term changes due to acid deposition, Geochim. Cosmochim. Ac., 58, 85-94, https://doi.org/10.1016/00167037(94)90448-0, 1994.

Mulder, J., van Breemen, N., and Eijck, H. C.: Depletion of soil aluminium by acid deposition and implications for acid neutralization, Nature, 337, 247-249, https://doi.org/10.1038/337247a0, 1989.

Nilsson, S. I., Miller, H. G., and Miller, J. D.: Forest growth as a possible cause of soil and water acidification: an examination of the concepts, Oikos, 39, 40-49, https://doi.org/10.2307/3544529, 1982.

Odén, S.: Nederbördens försurning, Dagens Nyheter 24 October, Stockholm, Sweden, 1967.

Oliver, B. G., Thurman, E. M., and Malcolm, R. L.: The contribution of humic substances to the acidity of natural waters, Geochim. Cosmochim. Ac., 47, 2031-2035, https://doi.org/10.1016/0016-7037(83)90218-1, 1983.

Posch, M. and Reinds, G. J.: A very simple dynamic soil acidification model for scenario analyses and target load calculations, Environ. Modell. Softw., 24, 329-340, https://doi.org/10.1016/j.envsoft.2008.09.007, 2009.

Rieder, S. R., Tipping, E., Zimmermann, S., Graf-Pannatier, E., Waldner, P., Meili, M., and Frey, B.: Dynamic modelling of the long term behaviour of cadmium, lead and mercury in Swiss forest soils using CHUM-AM, Sci. Total Environ., 468-469, 864876, https://doi.org/10.1016/j.scitotenv.2013.09.005, 2014.

Sverdrup, H.: Geochemistry, the key to understanding environmental chemistry, Sci. Total Environ., 183, 67-87, https://doi.org/10.1016/0048-9697(95)04978-9, 1996.

Sverdrup, H. and Warfvinge, P.: Weathering of primary silicate minerals in the natural soil environment in relation to a chemical weathering model, Water Air Soil Pollut., 38, 307-408, 1988.

Sverdrup, H. and Warfvinge, P.: Calculating field weathering rates using a mechanistic geochemical model PROFILE, Appl. Geochem., 8, 273-283, https://doi.org/10.1016/08832927(93)90042-F, 1993.

Sverdrup, H., Warfvinge, P., and Wickman, T.: Estimating the weathering rate at Gårdsjön using different methods, in Experimental reversal of Acid Rain Effects - The Gårdsjön Roof Project, edited by: Hultberg, H. and Skeffington, R., John Wiley \& Sons, 231-249, 1998.

Tipping, E.: WHAM - a chemical equilibrium model and computer code for waters, sediments and soils incorporating a discrete site/electrostatic model of ion-binding by humic substances, Comput. Geosci., 20, 973-1023, https://doi.org/10.1016/00983004(94)90038-8, 1994. 
Tipping, E.: CHUM - a hydrochemical model for upland catchments, J. Hydrol., 174, 305-330, https://doi.org/10.1016/00221694(95)02760-2, 1996.

Tipping, E.: Humic Ion-Binding Model VI: an improved description of the interactions of protons and metal ions with humic substances, Aquat. Geochem., 4, 3-48, https://doi.org/10.1023/A:1009627214459, 1998.

Tipping, E.: Cation binding by humic substances, Cambridge University Press, Cambridge, UK, 2002.

Tipping, E. and Chaplow, J. S.: Atmospheric pollution histories of three Cumbrian surface waters, Freshwater Biol., 57, 244-259, https://doi.org/10.1111/j.1365-2427.2011.02617.x, 2012.

Tipping, E. and Hurley, M. A.: A unifying model of cation binding by humic substances, Geochim. Cosmochim. Ac., 56, 36273641, https://doi.org/10.1016/0016-7037(92)90158-F, 1992.

Tipping, E. and Woof, C.: The distribution of humic substances between solid and aqueous phases of acid organic soils: a description based on humic heterogeneity and chargedependent sorption equilibria, J. Soil Sci., 42, 437-448, https://doi.org/10.1111/j.1365-2389.1991.tb00421.x, 1991.

Tipping, E., Woof, C., Backes, C. A., and Ohnstad, M.: Aluminium speciation in acidic natural waters: testing of a model for Al-humic complexation, Water Res., 22, 321-326, https://doi.org/10.1016/S0043-1354(88)90140-6, 1988.

Tipping, E., Berggren, D., Mulder, J., and Woof, C.: Modelling the solid-solution distributions of protons, aluminium, base cations and humic substances in acid soils, Eur. J. Soil Sci., 46, 77-94, https://doi.org/10.1111/j.1365-2389.1995.tb01814.x, 1995.
Tipping, E., Lawlor, A. J., and Lofts, S.: Simulating the long-term chemistry of an upland UK catchment: major solutes and acidification, Environ. Pollut., 141, 151-166, https://doi.org/10.1016/j.envpol.2005.08.018, 2006.

Tipping, E., Rothwell, J. J., Shotbolt, L., and Lawlor, A. J.: Dynamic modelling of atmospherically-deposited $\mathrm{Ni}, \mathrm{Cu}, \mathrm{Zn}, \mathrm{Cd}$ and $\mathrm{Pb}$ in Pennine catchments (northern England), Environ. Pollut., 158, 1521-1529, https://doi.org/10.1016/j.envpol.2009.12.026, 2010.

Wallman, P., Svensson, M. G. E., Sverdrup, H., and Belyazid, H.: FORSAFE - an integrated process-oriented forest model for long-term sustainability assessments, Forest Ecol. Manage., 207, 19-36, https://doi.org/10.1016/j.foreco.2004.10.016, 2005.

Warfvinge, P., Falkengren-Grerup, U., and Sverdrup, H.: Modelling long-term cation supply in acidified forest stands, Environ. Pollut., 80, 209-221, https://doi.org/10.1016/0269-7491(93)90041L, 1993.

Weng, L., Temminghoff, E. J. M., and van Riemsdijk, W. H.: Aluminum speciation in natural waters: measurement using Donnan membrane technique and modelling using NICA-Donnan, Water Res., 36, 4215-4226, https://doi.org/10.1016/S00431354(02)00166-5, 2002.

Wesselink, L. G. and Mulder, J.: Modelling Al-solubility controls in an acid forest soil, Solling, Germany. A simple model of soil organic matter complexation to predict the solubility of aluminium in acid forest soils, Ecol. Model., 83, 109-117, https://doi.org/10.1016/0304-3800(95)00090-I, 1995. 